\title{
1. Introduction: futures, now and then
}

\author{
Anis Ben Brik and Leslie A. Pal
}

\section{INTRODUCTION}

As the third wave of the transboundary coronavirus pandemic (COVID-19) drags on, policymakers and the public sector face their biggest test in generations - some say ever - as lives and livelihoods hang in a terrible, delicate balance. The COVID-19 pandemic, the most disruptive global event since the Great Depression and World War II, is involving many types of uncertainty: issues around data limitations; lack of consensus among experts and variations in expertise; the possibility of over- and under-reactions; different levels of trust in government; technical know-how; political support for certain kinds of interventions, and many others (Capano et al., 2020). In addition, the pandemic is causing the deepest global economic downturn since the 2008 financial crisis, leading to unemployment, food insecurity, increased global poverty and inequality. The economic costs are staggering: much of the world has fallen into recession, public debt levels are soaring, and future growth prospects have dimmed. In addition, the coronavirus has accelerated existing trends toward nationalist populism, authoritarianism, and tense relations among countries, and specifically with China. The pandemic has exacerbated the retreat from globalization, and raised new barriers to international trade, investment, and travel. However, the coronavirus pandemic also provides windows of opportunity to re-examine the roles of government in society. The new, emerging role of governments will be one that takes a strong and active state as given, where policymakers are prepared to adopt harsh measures of control and "do whatever it takes" to maintain public health, public order, and a functioning economy. States may become the "ultimate bearer of major societal risks" (Roberts, 2020).

The coronavirus pandemic is set to usher in a new era of bigger, more intrusive government. This kind of "protective state" implies more extensive social protection systems for a host of social, health, and economic threats, closer integration between states and markets, with states often taking a leading role, and a state administrative apparatus capable of managing this much more extensive agenda (Ansell, 2019).

In many countries, science, expert knowledge, and evidence-based decisions have returned to their rightful place in government decisions and the demand for scientific and technical expertise has increased as governments and the public search for certainty in understanding problems and choosing responses. The result is an increased politicization of scientific and technical information (Weible et al., 2020). Even before becoming President, Joe Biden named 13 scientists and public health specialists to a COVID-19 advisory board. Biden said in a statement that the board will "help shape my approach to managing the surge in reported 
infections; ensuring vaccines are safe, effective, and distributed efficiently, equitably, and free; and protecting at-risk populations" (Wadman and Cornwall, 2020).

But critical questions remain, and debates are raging about the future of policy sciences. One of the most important questions revolves around whether the post-COVID world will change public leadership, public administration, governance systems and public policies.

In his book, History of the Peloponnesian War, describing the impact of the great plague that struck Athens, Thucydides highlighted the declining capacity of institutions in limiting misconduct and opportunistic behaviors. He said, "the disease brought the beginning of great lawlessness ... no fear of god or the law of man restrained them for no man expected to live long enough to be tried and punished" (Morgan, 1994). Lasswell (1956) envisioned the policy sciences as providing insights into such situations, challenging and informing ongoing processes and decisions, and foretelling of future scenarios, all with the intent of steering government and society toward greater human dignity for all. It's clear that the pandemic has been a stress test for policy sciences and forces us to re-think some conventional theoretical approaches, as the chapters in this book show.

How successfully the post-pandemic world is managed will depend on how well governments and social systems are able to manage the transition. History suggests that transitions between phases of development can be harsh and uncertain. The postwar growth model took shape only after the Marshall Plan catalyzed its emergence. And the transition from the stagflationary 1970 s to the market-dominated growth model took a decade. The post-COVID years ahead will most likely be tough ones (Pisani-Ferry, 2020). The COVID-19 pandemic calls on government and citizen co-creation and co-production in the realization of policy goals. Policy sciences in a post-COVID world will have to accept that turbulence and uncertainty are the norm, not exceptions.

\section{PUBLIC LEADERSHIP, GOVERNANCE AND PUBLIC MANAGEMENT}

In mid-2021, when this book went to press, as several countries are in partial lockdowns to contain the coronavirus second wave, with many hoping that restrictions will begin to have an effect as intensive care units fill up, we are faced with a crucial question: Are our current public leadership, governance systems and public management working and, if not, what kind of model(s) do we want for tomorrow?

Governments are on the frontline in fighting the pandemic, using border controls, quarantines, shutting down much of the economy, local testing, contact tracing, treatment and isolation. Those that acted fastest and adopted more stringent measures have been most successful. Leaders who denied, dissembled, and delayed were responsible for thousands of preventable deaths. The status quo must change if we hope to survive the combined health, social, economic, political, and environmental crises at hand. The pandemic, hence, is a game changer for public leadership and management, as it reveals the demand for robust governance strategies to deal with turbulent problems and demonstrates the need for public sector reforms to support the robust governance of turbulence (Ansell et al., 2020). Post-COVID public management theory should embrace how we think about public governance. Weible et al. (2020) identified ten perspectives of the implications of the COVID-19 pandemic on policy sciences: policymaking; crisis response and management; global policymaking and 
transnational administration; policy networks; implementation and administration; scientific and technical expertise; emotions; narratives and messaging; learning; and policy success and failure. In addition, Dunlop et al. (2020) examined seven analytical themes that will deserve more attention in the post-pandemic era: policy design and instruments; policy learning; public service and its publics; organizational capacity; public governance; administrative traditions; and public sector reforms in multi-level governance. The policy sciences will have to come to grips with this new framing of public policies. How we theorize policy, understand and explain it, depends on the wider backdrop of the state systems within which policy is made and the expectations about its impact and success.

\section{THE NEXUS OF BIG DATA, PANDEMIC AND POLICY SCIENCES}

COVID-19 responses in many countries showed extensive use of emerging technologies (such as big data, AI, drones, $5 \mathrm{G}$, robotics, automated vehicles, block chain, etc.) linked to medical technologies. The exponential growth of big data and data analytics provides information and analytical capacity that would have been unimaginable even a few years ago. It is estimated that the number of devices connected to IP networks will be more than three times the global population by 2023. There will be 3.6 networked devices per capita by 2023 , up from 2.4 networked devices per capita in 2018. There will be 29.3 billion networked devices by 2023, up from 18.4 billion in 2018 (Cisco Systems Inc., 2020). The Global Big Data Analytics Market was valued at US\$37.34 billion in 2018 and is expected to reach US $\$ 105.08$ billion by 2027 at a compound annual growth rate of 12.3 percent throughout the forecast period, from 2019 to 2027. The number of firms investing in big data and AI more than US\$50 million rose from 27 percent in 2018 to 33.9 percent in 2019. In addition, the global spending on big data analytics is more than US\$180 billion in 2019 (Credence Research, 2020).

The COVID-19 pandemic stresses the importance of big data and data science techniques, such as machine learning algorithms to predict, assess and research changes on population and planet, as well as analytical capabilities to research and measure the impacts of policies and programs. Big data also play an ever more important role in research and evaluation, in large part because there are powerful new user-friendly analytic methods that make all the world's rapidly growing data accessible and more meaningful to an increasingly wider range of audiences (York and Bamberger, 2020). In addition, big data are often presented as a strategic opportunity for the design of new public policies, improving the quality and effectiveness of public services and using resources more efficiently (Azzone, 2018). In addition, big data and data science are raising basic questions about the future of privacy, the veracity of information, the future of work, and the future of policy science. Questions, thus, arise, about the application of big data in public policy.

\section{POST-COVID EDUCATION}

As the COVID-19 pandemic drags on, schools and universities around the world are facing big losses across a range of income sources and investments. Policymakers all over the world are grappling with distance learning provision and safe school reopening. The crisis has created "the largest disruption of education systems in history, affecting nearly 1.6 billion learners in more than 190 countries and all continents" (United Nations, 2020). Closures of schools 
and other learning spaces have impacted 94 percent of the world's student population, and up to 99 percent in low and lower-middle income countries (United Nations, 2020). The World Bank predicted that COVID-19 could result in a loss of 0.6 years of schooling, adjusted for quality, bringing down the effective years of basic schooling that children achieve during their schooling life from 7.9 years to 7.3 years, and close to 7 million students from primary up to secondary education could drop out due to the income shock of the pandemic alone (Azevedo et al., 2020). An estimated 40 percent of the poorest countries failed to support learners at risk during the COVID-19 crisis (UNESCO, 2020). As of mid-April of 2020, fewer than 25 percent of low-income countries were providing any type of remote learning, and a majority that did used TV and radio (Vegas, 2020). In addition, COVID-19 has put digital technology at the heart of education. Technology has also been crucial for ongoing communication between schools and students throughout the pandemic. However, evidence shows that it is clear that this agenda must be ruthlessly focused on when and how digital technology can be used to improve outcomes for learners and teachers (Quilter-Pinner and Ambrose, 2020).

This book examines the future of public policy both as an intellectual enterprise but also as pedagogy, the teaching and training of policy professionals. The book addresses conceptual, theoretical, critical and practical assessments from the vantage point of the growth of public policy as a field of study; trends, critical junctures, potential tipping points and possible trajectories; emerging threats to public policymaking and the growth drivers that have seen policy studies emerge as a leading area of inquiry in the social sciences. The book brings a critical perspective to the emerging challenges of evidence-based policymaking; changes in the locus of authority in terms of the rise of transnational issues; changes in the nature of governance and the role of government; and changes in civil-society, representation and political contestation. Overall, this book is a critical stocktaking and reflection on the state of the policy science, its strengths and weaknesses, and where it may or should be heading in the future, by responding to the following questions: Where are we at in terms of the intellectual enterprise of public policy and where are we going? How is the field evolving and what is driving its intellectual evolution - and to what end? Are there weaknesses in this enterprise, blind spots, or fields of inquiry receiving too little or too much attention? How do we account for the popularity of policy studies, arguably in contexts where governmentality has been declining or at least made increasingly problematic by the rise of various forces that challenge the legitimacy of traditional forms of institutional authority and governance? Is what we teach relevant to where graduates of policy programs/schools find employment? To what extent is public policy establishing itself as a field in the non-Western world? To what extent do regulatory intermediaries serve to frame, extend, and limit collective goods when compared with rule-takers and rule-makers? What are the challenges and possible solutions for democratic regulatory control of regulatory intermediaries?

\section{OVERVIEW OF THE BOOK}

The chapters in this volume are structured around ten topics. Some of the chapters present new empirical findings; others provide critical reviews. Each chapter begins with a broad overview of the topic and goals of the chapter, presents background research on the topic from the international literature, provides new empirical data or reviews empirical studies, suggests 
implications for policy and practice and ends with implications for understanding the future of policy science. A brief description of each chapter follows.

First, Goyal, El-Taliawi, and Howlett describe big data techniques and their applications in public policy and analyse the extent to which such techniques are taught in policy programs around the world. Based on a bibliometric review of nearly 2,500 publications on big data in public policy and content analysis of course titles and descriptions in 122 programs, the authors argue that big data creates a paradigm shift in public policy research and practice, with the development of new epistemologies and new types of analyses. The chapter shows a clear pedagogical gap in the offering of big data courses, high geographic variation in the diffusion of big data analytics in public policy pedagogy as well as limited transnational collaboration. In addition, the chapter presents findings that contribute to understanding how the appropriate engagement with the big data phenomenon can help the policy sciences remain relevant and move a step closer to integrating policy research, pedagogy, and practice.

Next, Hartley and Ahmad examine trends in the proliferation of degree and executive education programs in policy studies through the perspective of two generations of civil service professionalization. The chapter applies the structure-institutions-actors perspective to analyse the case of Brunei's Institute of Policy Studies. The chapter shows how global ideological movements shape the choice sets available to organizations and individuals as actors. The authors argue that neo-professionalization should be considered in discussions about $21 \mathrm{st}$ century policy education.

Howlett and Jarvis examine the history of policy sciences as well as the reasons for its expansion in regions as varied as Latin America, Australia and Asia. The chapter shows that the fabric and staffing of policy schools is linked to the institutional machinations of institution building, the problems of resource mobilization, the circumstance of available faculty and their interests, turf wars, and the intersection of events and interests. The growth of the field, however, faces several challenges, many of which are likely to be geographically discrete, such as ideational, physical re-accommodation, resources, institutional path dependencies, and leadership.

Nair, El-Taliawi and Van der Wal address public policy education in the non-Western world in terms of a possible divergence from a Western school of thought, branching out from disciplinary foundations and the emergence of public policy as a unique, independent field of inquiry and the response of policy research and practice to new and emerging policy challenges, such as the COVID-19 pandemic. The chapter presents the findings of a comparison of 46 policy schools in Africa and the Middle East, Asia and Latin America in terms of geographic dispersion, their years of founding, their disciplinary foci, degree offerings, public versus private nature, executive education offerings, as well as the macro-political context in which schools are embedded. The chapter shows that the majority of policy schools in Africa and the Middle East, Asia and Latin America are not replicating Western models, but rather are home-grown through their course content, dissertation topics requirements, and faculty hiring.

Kuecker and Hartley focus on the epistemic foundations of public policy as a practiced and studied discipline. The chapter examines how the convergence of wicked problems has forced society to contemplate the effectiveness of modernist epistemics and problem-framing as embodied by the development disaster risk reduction paradigm. The authors argue that the flawed assumptions and perspectives of the development narrative are reproduced within dis- 
aster risk reduction by a power-knowledge nexus that fortifies the status quo while fashioning the image of progress through performative and quasi-participatory mechanisms. The chapter proposes a pathway for policy sciences scholarship that examines how dominant social or economic paradigms (e.g., capitalism) underlying policy thinking survive through multiple narrative reframings.

Vesely's chapter explores how the concept of "policy practice" can bridge the gap between theory and empirical findings. Using mixed methodology, the chapter presents several practices that have broader relevance, and bridge micro- and macro-levels. The chapter argues that meso-level analysis in policy sciences is often neglected as compared with macro- and micro-level analysis. Veselý argues that the concept of policy practice is very helpful in opening the "backstage" of policy formulation process. In addition, the chapter discusses how policy practice, as a meso-concept between macro-structures and individual agency, might explain some of the variation among countries in terms of their response to COVID-19 pandemic.

Brian W. Head's chapter focuses on policy expertise and policy markets. He argues that the future of democratic institutions and the "good governance" of policymaking are under threat from several sources, including populism, fake news, and hyper-partisanship. The experience of addressing the COVID-19 pandemic shows that vigorous debates with multiple voices are necessary to acknowledge the twin goals of legitimacy and effectiveness. In addition, the chapter argues that policy research for democratic governance needs to pay attention to enhancing outcomes-based legitimacy, by competently delivering benefits and by protecting well-being and fairness; while at the same time improving democratic process legitimacy, by upholding commitments to accountability, integrity, transparency and due process.

Rechkemmer's chapter adds a dimension to policy thinking that is still oddly sub rosa, policymaking at the global level. If the policy sciences have at least one, clear path to climb in the future, it's towards a better connection between domestic and global policy processes. The chapter explores the utility of learning from the evolution of global sustainability governance (GSG), which is characterized by resilience, flexibility, and adaptability, resulting in the largest regime complex in global policy, whose flagship is Sustainable Development Goals (SDGs), and it applies those lessons to inform future policy research. Rechkemmer argues that the future of policy sciences should include a generic perspective that learns from the history, evolution and phenomenology of GSG - well beyond the actual field of sustainable development.

Dunlop and Radaelli pose the question "what is a policy scholar for?", probing the role of researchers, vision, and tasks by looking at five key verbs that define the role of the policy scholar: learning, analysing, advising, empowering and reflecting. The chapter describes the trends that are undermining good policy governance and policy capacities to address crises such as the COVID-19 pandemic; and the weakened legitimacy of policy processes and solutions. The chapter proposes re-orienting the research agenda of the policy sciences towards addressing these challenges and, in particular, seeking to strengthen the role of knowledge and experience in the policy process, while also strengthening the legitimacy of public policymaking through open and transparent processes. The chapter argues that the future of the policy sciences should find an anchor in a reflection on the roles of researchers, questioning vision, tasks, and the role of policy sciences in society. 
Finally, the book concludes by providing a "future tense" for the policy sciences and a new syntax for public policy, which will have to grapple with a new role for the state; changes in policy fields, issues and debates; and the stress tests experienced by our conventional theories. This final chapter argues that the policy sciences will have to come to grips with a new framing of policy processes and state competences, as well as the challenges of organizing policy advice to serve that purpose. The final chapter also argues that the future of the policy sciences will demand a new grammar, a future tense that embraces morphologies of mayhem and turbulence, a syntax of synergies, and a linguistic turn towards deeper questions.

\section{CONCLUSION}

The future of the policy sciences is not what it used to be. The pandemic is both a rupture and an opportunity, magnifying some of the weaknesses in the discipline circa 2019, but also suggesting pathways to overcome them. In late 2019, when the authors first met to present the papers that eventually became the chapters in this book, there was a mixed sense of accomplishment and of stasis. The academic and scientific field of the policy sciences had grown markedly, as evidenced by the global spread of policy programs, the explosion of journals and research, and the achievement of a solid core of accepted frameworks and conventional debates. The demand for policy advice and policy expertise among governments had grown as well, and "capacity building" and "innovation" were on every public sector reform agenda. At the same time, however, the 2008 financial crisis had sparked global turmoil, political disruptions, and populist spasms. The policy landscape was increasingly afflicted by wicked problems, chaos, and complexity. No global policy summit was complete without a worrying list of "global governance and policy challenges." There was an evident gap between theory and practice. The now conventional frameworks and accepted approaches to policy design and policy thinking seemed oddly exhausted and flat.

COVID-19 is the ultimate disruptor. As the above summary of chapters shows, it magnified existing unease in the discipline, but has also amplified the importance of getting down to business and taking the discipline to the next level. As we note in our concluding chapter, the pandemic has exposed fundamental issues of governance and democracy, of the balance of local and global, of abiding inequalities, and a host of pre-existing issues that have been festering in advanced capitalist economies for the last decade. By the time this book is published, it may very well be that the pandemic will soon be behind us. Vaccines became available through 2021 and, with luck and effort, will be administered around the world. Economies will revive, travel will resume, and people will seize the "normal". From a policy perspective however, COVID-19 was a near-death experience for bodies politic that were already in poor health. In late 2020, variations on a slogan began to emerge among think tanks (e.g., Brookings) and political campaigns (e.g., Biden's). It was to "rebuild better," or to "build back better," or to "rebuild, reinvent, redesign."

The policy sciences will have to do the same.

\section{REFERENCES}

Ansell, C. (2019). The Protective State. Cambridge: Cambridge University Press. 
Ansell, C., Sørensen, E., \& Torfing, J. (2020). The COVID-19 pandemic as a game changer for public administration and leadership? The need for robust governance responses to turbulent problems. Public Management Review, 1-12. doi:10.1080/14719037.2020.1820272

Azevedo, J. P., Hasan, A., Goldemberg, D., Iqbal, S. A., \& Geven, K. (2020). Simulating the potential impacts of COVID-19 school closures on schooling and learning outcomes: A set of global estimates. World Bank, Washington, DC. Available at: https://openknowledge.worldbank.org/handle/10986/ 33945

Azzone, G. (2018). Big data and public policies: Opportunities and challenges. Statistics \& Probability Letters, 136, 116-120.

Capano, G., Howlett, M., Jarvis, D. S., Ramesh, M., \& Goyal, N. (2020). Mobilizing policy (in) capacity to fight COVID-19: Understanding variations in state responses. Policy and Society, 39(3), 285-308.

Cisco Systems Inc. (2020). Cisco annual internet report (2018-2023). White Paper. Available at: https:// www.cisco.com/c/en/us/solutions/collateral/executive-perspectives/annual-internet-report/white -paper-c11-741490.html

Credence Research (2020). Global big data analytics market size, market share, application analysis, regional outlook, growth trends, key players, competitive strategies and forecasts, 2019 to 2027. Available at: https://www.credenceresearch.com/report/big-data-analytics-market\#top

Dunlop, C. A., Ongaro, E., \& Baker, K. (2020). Researching COVID-19: A research agenda for public policy and administration scholars. Public Policy and Administration, 35(4), 365-383.

Lasswell, H. D. (1956). The political science of science: An inquiry into the possible reconciliation of mastery and freedom. The American Political Science Review, 50(4), 961-979.

Morgan, T. E. (1994). Plague or poetry? Thucydides on the epidemic at Athens. Transactions of the American Philological Association (1974-), 124, 197-209.

Pisani-Ferry, J. (2020). The Challenges of the Post-Pandemic Agenda. Bruegel-Blogs.

Quilter-Pinner, H. \& Ambrose, A. (2020). The 'new normal': The future of education after Covid-19, IPPR. Available at: http://www.ippr.org/research/publications/the-new-normal

Roberts, A. (2020). The third and fatal shock: How pandemic killed the millennial paradigm. Public Administration Review, 80(4), 603-609. doi:10.1111/puar.13223.

UNESCO (2020). Global Education Monitoring (GEM) Report, 2020: Inclusion and education: all means all. Available at: https://unesdoc.unesco.org/ark:/48223/pf0000373718

United Nations (2020). Education during COVID-19 and beyond. Available at: https://www.un .org/development/desa/dspd/wp-content/uploads/sites/22/2020/08/sg_policy_brief_covid

-19_and_education_august_2020.pdf

Vegas, E. (2020). School Closures, Government Responses, and Learning Inequality around the World during COVID-19. Washington, DC: Brookings Institution. Available at: https://www.brookings.edu/ research/school-closures-government-responses-and-learning-inequality-around-the-world-during -covid-19/

Wadman, M. \& Cornwall, W. (2020). With inauguration 10 weeks away, Biden's pandemic plans face agonizing wait. Available at: https://www.sciencemag.org/news/2020/11/inauguration-10-weeks -away-biden-s-pandemic-plans-face-agonizing-wait

Weible, C. M., Nohrstedt, D., Cairney, P., Carter, D. P., Crow, D. A., Durnová, A. P., ..., Stone, D. (2020). COVID-19 and the policy sciences: Initial reactions and perspectives. Policy Sciences, 53, 225-241. doi:10.1007/s11077-020-09381-4

York, P. \& Bamberger, M. (2020). Measuring results and impact in the age of big data: The nexus of evaluation, analytics, and digital technology. The Rockefeller Foundation. Available at: https://www .rockefellerfoundation.org/wp-content/uploads/Measuring-results-and-impact-in-the-age-of-big-data -by-York-and-Bamberger-March-2020.pdf 